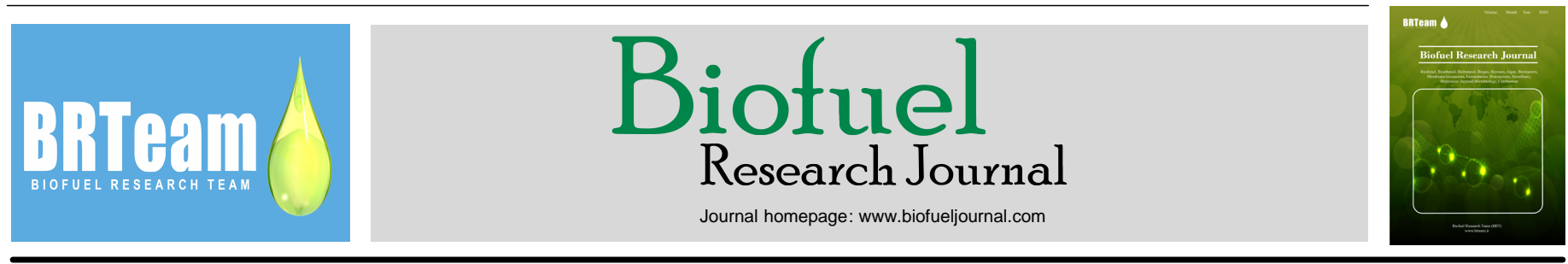

Original Research Paper

\title{
Development and evaluation of a novel low power, high frequency piezoelectric-based ultrasonic reactor for intensifying the transesterification reaction
}

\author{
Mortaza Aghbashlo ${ }^{1, \dagger}, *$, Meisam Tabatabaei ${ }^{2,3, * *}$, Soleiman Hosseinpour ${ }^{1, *}$, Seyed Sina Hosseini ${ }^{1}$, Akram Ghaffari ${ }^{2}$, \\ Zahra Khounani ${ }^{2,3}$, Pouya Mohammadi ${ }^{3}$
}

${ }^{1}$ Department of Mechanical Engineering of Agricultural machinery, Faculty of Agricultural Engineering and Technology, College of Agriculture and Natural Resources, University of Tehran, Karaj, Iran.

${ }^{2}$ Agricultural Biotechnology Research Institute of Iran (ABRII), Agricultural Research, Education, and Extension Organization (AREEO), Karaj, Iran.

${ }^{3}$ Biofuel Research Team (BRTeam), Karaj, Iran.

\section{HIGHLIGHTS}

A novel low power, high frequency piezoelectricbased ultrasonic reactor was investigated for the first time for rapid biodiesel production. $>6: 1$ alcohol/oil molar ratio, 10 min sonication time, and $60{ }^{\circ} \mathrm{C}$ temperature as the optimal conditions. $>$ Conversion efficiency of $97.12 \%$ at a specific energy consumption of as low as $378 \mathrm{~kJ} / \mathrm{kg}$ was achieved.

$>$ Promising replacement for high power, low frequency ultrasonic systems was introduced.

\section{GRAPHICAL ABSTRACT}

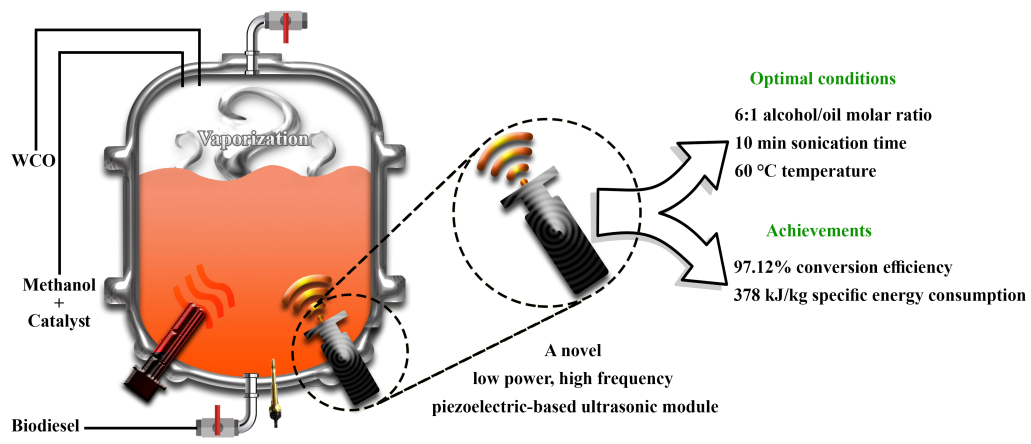

\section{ARTICLE INFO}

\section{Article history:}

Received 16 September 2016

Received in revised form 29 October 2016

Accepted 21 November 2016

Available online 1 December 2016

\section{Keywords:}

Biodiesel

Transesterification process

Process intensification

Piezoelectric-based ultrasonic reactor

Low power, high frequency ultrasonic system

Specific energy consumption

\begin{abstract}
In this study, a novel low power, high frequency piezoelectric-based ultrasonic reactor was developed and evaluated for intensifying the transesterification process. The reactor was equipped with an automatic temperature control system, a heating element, a precise temperature sensor, and a piezoelectric-based ultrasonic module. The conversion efficiency and specific energy consumption of the reactor were examined under different operational conditions, i.e., reactor temperature $\left(40-60{ }^{\circ} \mathrm{C}\right)$, ultrasonication time (6-10 min), and alcohol/oil molar ratio (4:1-8:1). Transesterification of waste cooking oil (WCO) was performed in the presence of a base-catalyst (potassium hydroxide) using methanol. According to the obtained results, alcohol/oil molar ratio of $6: 1$, ultrasonication time of $10 \mathrm{~min}$, and reactor temperature of $60{ }^{\circ} \mathrm{C}$ were found as the best operational conditions. Under these conditions, the reactor converted WCO to biodiesel with a conversion efficiency of $97.12 \%$, meeting the ASTM standard satisfactorily, while the lowest specific energy consumption of $378 \mathrm{~kJ} / \mathrm{kg}$ was also recorded. It should be noted that the highest conversion efficiency of $99.3 \%$, achieved at reactor temperature of $60{ }^{\circ} \mathrm{C}$, ultrasonication time of $10 \mathrm{~min}$, and alcohol/oil molar ratio of $8: 1$, was not favorable as the associated specific energy consumption was higher at $395 \mathrm{~kJ} / \mathrm{kg}$. Overall, the low power, high frequency piezoelectric-based ultrasonic module could be regarded as an efficient and reliable technology for intensifying the transesterification process in terms of energy consumption, conversion efficiency, and processing time, in comparison with high power, low frequency ultrasonic system reported previously. Finally, this technology could also be considered for designing, developing, and retrofitting chemical reactors being employed for non-biofuel applications as well.
\end{abstract}

(c) 2016 BRTeam. All rights reserved. * Corresponding author at: Tel.: +98 26 32801011, E-mail address: maghbashlo@ @ut.ac.ir (M. Aghbashlo); Tel: +98 9132865342, E-mail address: meisam_tab@yahoo.com \&
meisam_tabatabaei@ abrii.ac.ir (M. Tabatabaei); Tel.: +98 2632801011 , E-mail address: shosseinpour@ ut.ac.ir (S. Hosseinpour)

$\dagger$ These authors contributed equally.

Please cite this article as: Aghbashlo M., Tabatabaei M., Hosseinpour S., Hosseini S.S., Ghaffari A., Khounani Z., Mohammadi P. Development and evaluation of a novel low power, high frequency piezoelectric-based ultrasonic reactor for intensifying the transesterification reaction. Biofuel Research Journal 12 (2016) 528-535. DOI: 10.18331/BRJ2016.3.4.7 


\section{Introduction}

The increasing energy demands along with the exhaustion of fossil fuel resources are steadily pushing researchers to explore environmentally-clean and economically-viable alternative energy carriers in order to fill the gap between the energy demand and supply in a sustainable manner. Among alternative energy sources developed to date, biodiesel has gained a growing attention as a good substitute to mineral diesel because of providing ecofriendly combustion, having similar physicochemical properties to those of mineral diesel, and being renewable, biodegradable, non-toxic, and lubricant (Aghbashlo et al., 2015). However, there are many damning reports published in the last decade where biodiesel production from food- and feed-grade feedstocks is portrayed as the main culprit for the food price hikes and shortages because of a controversial competition over the use of land and water (Collins, 2008; Mitchell, 2008). In order to address this issue, the use of waste cooking oil (WCO) as a promising alternative source to the first generation feedstocks has gained increasing popularity due to its environmentally-acceptable and economically-viable features (Aghbashlo and Demirbas, 2016).

Transesterification of triglycerides or fatty acids with an alcohol in the presence of a homogeneous or heterogeneous catalyst using a mechanicallystirred reactor is one of the most popular procedures applied commercially for synthesizing biodiesel from various feedstocks. However, mechanical stirring method require a long processing time and a huge amount of energy to boost the interfacial region between alcohol and oil due to their low immiscibility as the main factor affecting the yield of the transesterification process. In order to meet the increasing biodiesel demands worldwide and to accelerate the transesterification reaction, various techniques have been developed using heterogeneous catalysts including alcohol supercritical temperature, transesterification via radio frequency microwave, alcohol reflex temperature, and ultrasonication (Ramachandran et al., 2013). Amongst the technologies developed to date, ultrasound technique is taken into account as one of the most promising process-intensification technologies due to its low cost and high safety. Ultrasonic irradiations can efficiently reduce the required process time and temperature compared with the mechanically-stirred transesterification process through strengthening the mass transfer of the liquid-liquid systems (Yin et al., 2012). The irradiated ultrasound waves create micro fine bubbles in the phase boundary of the two immiscible liquids which in turns facilitate and intensify the emulsification process due to a high amount of energy released by the asymmetric collapse of the generated microbubbles.

In this sense, numerous research attempts have been conducted to apply high power, low frequency ultrasound technology for biodiesel production from various feedstocks in recent years. For instance, Deshmane et al. (2008) investigated the methylation of palm fatty acid distillate in the presence of concentrated $\mathrm{H}_{2} \mathrm{SO}_{4}$ using ultrasonic irradiations at a frequency of $22 \mathrm{kHz}$ and a power of $120 \mathrm{~W}$. In another study, Santos et al. (2010) produced methyl esters from Oreochromis niloticus oil using a low-frequency (40 kHz), highintensity ultrasound system. Furthermore, Salamatinia et al. (2012) intensified the biodiesel production process using ultrasonic irradiations at $20 \mathrm{kHz}$ and $200 \mathrm{~W}$ in the presence of SrO catalyst. Later, Maddikeri et al. (2013) applied an ultrasonic horn at a frequency of $22 \mathrm{kHz}$ and power of $750 \mathrm{~W}$ to intensify the methylation of WCO with methyl acetate in the presence of potassium hydroxide as catalyst. In addition, Michelin et al. (2015) explored the fatty acid ethyl esters production process from Macauba coconut oil using solventfree enzymatic (immobilized lipase) transesterification reaction under ultrasound irradiations ( $40 \mathrm{kHz}$ and $132 \mathrm{~W}$ ). Recently, Subhedar and Gogate (2016) synthesized biodiesel from the WCO using methyl acetate and immobilized lipase by means of ultrasound irradiations ( $20 \mathrm{kHz}$ and $120 \mathrm{~W})$. More comprehensive information could be found in a review paper published by Ramachandran et al. (2013) on the application of ultrasound technology for intensifying the transesterification process from various feedstocks.

Although the above-mentioned studies revealed the potential of ultrasound technology for making biodiesel from oils, the required processing time and energy can still be discounted by developing innovative and emerging technologies. Therefore, the objective of the current study was to develop and evaluate a low power, high frequency piezoelectric-based ultrasonic reactor for enhanced transesterification process. Moreover, the effects of experimental variables, i.e., ultrasonication time $(6-10 \mathrm{~min})$, reaction temperature $\left(40-60{ }^{\circ} \mathrm{C}\right)$, and alcohol/oil molar ratio $(4: 1-8: 1)$ on the conversion efficiency and specific energy consumption of the WCO to methyl esters were also studied. To the best of our knowledge, this is the first study reporting the use of a low power $(31 \mathrm{~W})$ and high frequency (1.7 MHz) piezoelectric-based ultrasonic module for the intensification of the transesterification reaction. In fact, most research attempts were focused on using high power (100-2400 W) and low frequency (20-40 $\mathrm{kHz}$ ) ultrasound systems to convert triglycerides into fatty acids alkyl esters. Accordingly, the ultrasound system introduced herein can be a more efficient and reliable technology over those reported in the literature from the energy consumption and processing time perspectives. The findings of the current survey would be helpful to designers and engineers in applying the proposed low power, high frequency ultrasound technology for biodiesel production in an environmentally-sustainable and economically-viable manner as well as in retrofitting the available systems.

\section{Materials and Methods}

\subsection{Materials}

The WCO containing linoleic acid (50.57\%), oleic acid (33.94\%), and palmitic acid (15.48\%) was obtained from a local restaurant (Karaj, Iran). The FFA content was determined at about $1 \%$ using the standard titrimetry method (Tiwari et al., 2007). Filtration using normal sieves was carried out twice to remove food debris from the WCO. Moreover, the water present was also eliminated. Methanol (99\%) and potassium hydroxide used throughout this study were obtained from Merck (Germany).

\subsection{Piezoelectric-based ultrasonic reactor, biodiesel production methodology, and analysis}

In this study, a novel low power, high frequency piezoelectric-based ultrasonic reactor was constructed and evaluated for biodiesel production from WCO. A schematic representation of the developed cylindricallyshaped piezoelectric-based ultrasonic reactor is manifested in Figure 1. The stainless steel (S316) chamber used had a total volume of $5 \mathrm{~L}$ with a wall thickness of $2 \mathrm{~mm}$. The reactor was $20 \mathrm{~cm}$ in diameter and $16 \mathrm{~cm}$ in height. The heating of the liquid media inside the reactor was carried out by means of a spiral-shaped $500 \mathrm{~W}$ heating element. In order to control and adjust the temperature of the liquid media, a digital waterproof

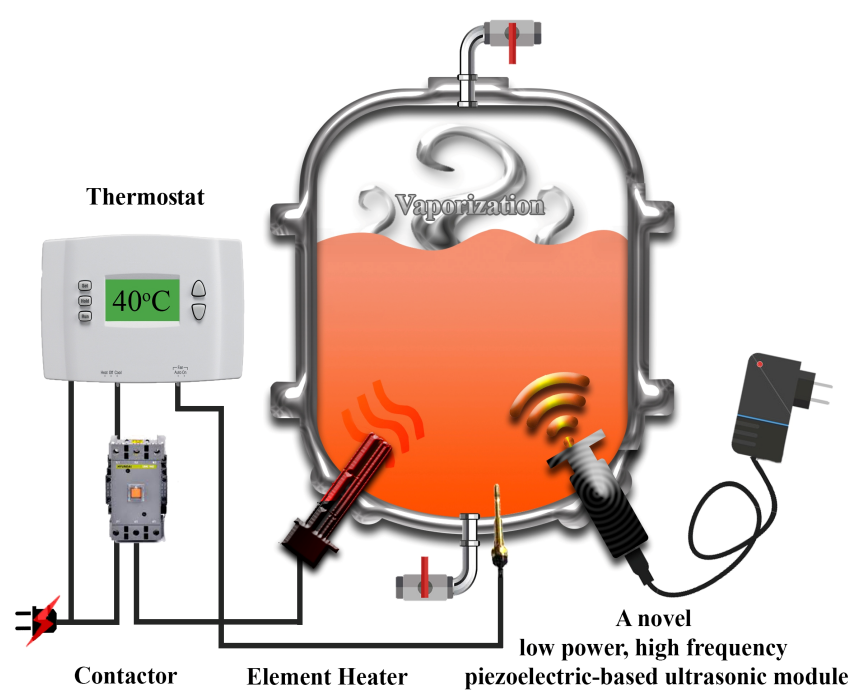

Fig.1. A schematic representation of the high-frequency, low-power piezoelectric-based ultrasonic reactor developed in this study for the transesterification of WCO. 
temperature sensor with a precision of $0.1{ }^{\circ} \mathrm{C}$ was located within the chamber. Moreover, automatic temperature controlling of the reactor was performed using a $5 \mathrm{~W}$ digital thermostat. A low-power $(31 \mathrm{~W})$, high-frequency $(1.7$ $\mathrm{MHz}$ ) piezoelectric-based ultrasonic module was installed within the chamber in order to accelerate the methylation process of WCO. The specifications of the equipment and instruments used in the construction of the reactor are summarized in Table 1.

Table 1.

Specifications of the equipment and instruments used in the construction of the reactor.

\begin{tabular}{|c|c|}
\hline Equipment and instruments & Specifications \\
\hline Ultrasonic module & $\begin{array}{l}\text { Size: } \phi 46 \times 22.9 \text { (Piezo: } \phi 20 \times 1.2 \text { ) mm } \\
\text { Resonant Frequency: } 1.70 \mathrm{MHz} \\
\text { Resonant Impedance: }<2 \Omega \\
\text { Coupling factor: }>52 \% \\
\text { Electrostatic capacity: } 1800 \mathrm{pF} \\
\text { Spray volume: }<380 \mathrm{~mL} / \mathrm{h}\end{array}$ \\
\hline Electrical heater & $\begin{array}{l}\text { Power: } 500 \mathrm{w} \\
\text { Type: Tubular heating element } \\
\text { Material: Stainless steel }\end{array}$ \\
\hline Thermocouple & $\begin{array}{l}\text { Accuracy: } 0.1 \text { degree of Celsius } \\
\text { Material: Stainless steel }\end{array}$ \\
\hline Controller and displayer & $\begin{array}{l}\text { Model: SU-105 IP } \\
\text { Temp. range: }-50.0{ }^{\circ} \mathrm{C} \sim 150{ }^{\circ} \mathrm{C} \\
\text { Output: Main/Aux (DC12V) } \\
\text { Main/Aux(Relay) }\end{array}$ \\
\hline
\end{tabular}

In the current survey, the effects of ultrasonication time (6, 8, and $10 \mathrm{~min})$, reaction temperature $\left(40,50\right.$, and $\left.60{ }^{\circ} \mathrm{C}\right)$, and alcohol/oil molar ratio $(4: 1,6: 1$, and 8:1) were investigated on the specific energy consumption and conversion efficiency of WCO to methyl esters. An initial volume of 1500 $\mathrm{mL}$ of the liquid medium was considered for all experiments in order to avoid any volume effects on the studied parameters. A balance with a precision of $0.001 \mathrm{~g}$ was used to weigh all materials used in the experiment. A schematic representation of the experimental methodology employed in the present study for the production and analysis of biodiesel from WCO is provided in Figure 2.

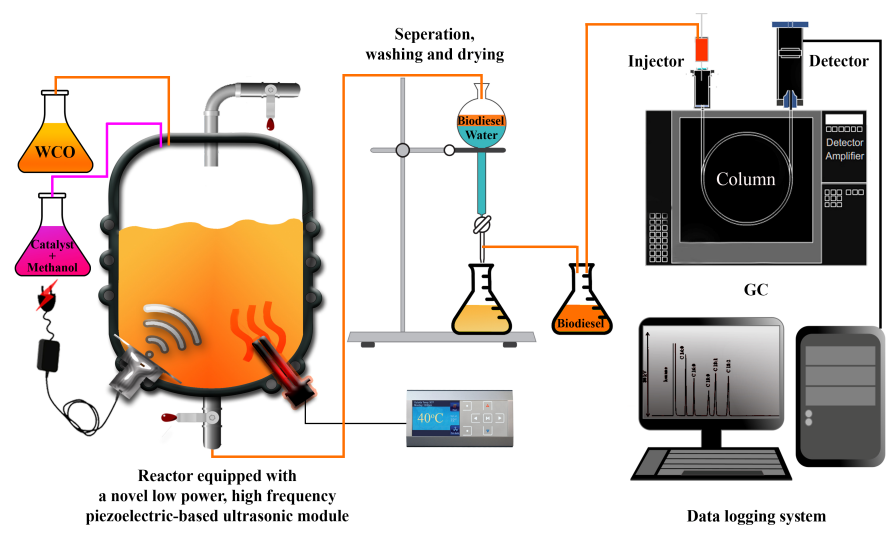

Fig.2. A schematic illustration of the experimental methodology applied in the present survey for production and analysis of biodiesel from WCO.

To synthesis biodiesel, first potassium hydroxide (1 wt.\%) and methanol were mixed for $2 \mathrm{~min}$ by a magnetic stirrer. The resultant potassium methoxide was then gradually transferred to the reactor together with the WCO. After heating the liquid to the desired temperature, the ultrasound module was turned on to intensify the transesterification process. The electrical power utilized by the system was recorded during each experiment in order to compare the energy consumption of the performed trials. Afterwards, the reaction products were immediately drained from the reactor and transferred into an ice-bath for $30 \mathrm{~min}$ to cease the transesterification process. In order to segregate crude glycerol from biodiesel, the reaction products were left for $2 \mathrm{~h}$. The unreacted methanol, formed soap, and potassium hydroxide were then separated from the produced biodiesel by thrice washing the crude biodiesel with $500 \mathrm{~mL}$ hot water $\left(60{ }^{\circ} \mathrm{C}\right)$. Finally, the purified biodiesel was dehydrated in an oven at $80{ }^{\circ} \mathrm{C}$ for $4 \mathrm{~h}$ in order to vaporize the absorbed water.

The conversion efficiency of the biodiesel samples was determined by means of a Varian CP-3800 gas chromatograph (GC) (Varian, Inc., Palo Alto, CA) equipped with a CP-Sill 88 fused silica column $(100 \mathrm{~m}, 0.25$ $\mathrm{mm}$ I.D., film thickness $0.25 \mu \mathrm{m}$ ) and a flame ionization detector (FID) detector. More specifically, $0.5 \mathrm{~mL}$ of $n$-hexane solution containing lauric acid methyl ester as internal standard $(4 \mathrm{mg} / \mathrm{mL})$ was added into each preweighed biodiesel sample and $1 \mu \mathrm{L}$ of the mixture was injected into the GC (split mode with a split ratio of 80:1). Nitrogen was used as the carrier gas. The purity of the produced biodiesel was the computed using the following equation (Wang et al., 2006):

Purity $(\%)=\left(\frac{\text { area of FAME } / \text { area of reference } \times \text { weight of reference }}{\text { weight of biodiesel }}\right) \times 100$

The computed conversion efficiency was used to calculate the molar fraction of methyl esters, triglyceride, diglyceride, and monoglyceride, and glycerin. In order to simplify the mass balance calculations, it was postulated that the FFA (linoleic acid) of the WCO was completely reacted with potassium hydroxide generating soap and water at the end of experiment. Moreover, the molar fractions of triglyceride, diglyceride, and monoglyceride were assumed to be equal at the end of the reaction.

\section{Results and discussions}

Table 2 tabulates the full mass balance for the low power, high frequency piezoelectric-based ultrasonic biodiesel synthesis from WCO at various alcohol/oil molar ratios, ultrasonication times, and reactor temperatures. It is obvious from the data presented in the table that the reactor could satisfactorily methylate the WCO to biodiesel at the highest level of alcohol/oil molar ratio, ultrasonication time, and reactor temperature, while the transesterification reaction was sluggish at the lowest levels of these parameters. The maximum amount of fatty acids methyl esters were synthesized at alcohol/oil ratio of $8: 1$, ultrasonication time of $10 \mathrm{~min}$, and reactor temperature of $60{ }^{\circ} \mathrm{C}$. However, mass balance or even conversion efficiency could lead to misleading conclusions when analyzing a reactor employed for biodiesel production. This could be ascribed to the fact that these parameters recognize the optimum operational conditions on the basis of the process yield alone, while such conditions might have the highest energy requirement.

Figure 3 shows the effects of experimental variables on the conversion efficiency of the WCO to biodiesel. Conversion efficiency varied between $9.73 \%$ and $99.3 \%$ and increased as the alcohol/oil molar ratio elevated. Even though the required stoichiometric alcohol/oil molar ratio is $3: 1$ for the complete conversion of triglyceride to fatty acids esters, higher ratios (excess alcohol) should be applied to drive the reaction towards achieving higher yields. It should also be noted that further increase of alcohol/oil molar ratio beyond an optimal value could lead to only a marginal increase in the conversion efficiency and could also reverse the transesterification reaction due to an excessive dilution of oil. Gupta et al (2015) noted that the access of triglycerides molecules to active site of the catalyst used was diminished at higher alcohol/oil molar ratios due to oil dilution. Moreover, further increasing the alcohol/oil ratio could result in difficulties during biodiesel purification and separation process.

In the present study, a steady increase in the conversion efficiency was observed from $55.53 \%$ to $97.12 \%$ by increasing the alcohol/oil molar ratio from $4: 1$ to $6: 1$ at the constant temperature of $60{ }^{\circ} \mathrm{C}$ 
Table 2.

Full mass balance (g) for the low power, high frequency piezoelectric-based ultrasonic biodiesel processor.

\begin{tabular}{|c|c|c|c|c|c|c|c|c|c|c|c|c|c|c|c|c|c|}
\hline \multicolumn{3}{|c|}{ Operational conditions } & \multicolumn{4}{|c|}{ Inputs (g) } & \multicolumn{11}{|c|}{ Outputs (g) } \\
\hline $\begin{array}{l}\mathrm{A} / \mathrm{O}^{1} \\
\text { Molar } \\
\text { ratio }\end{array}$ & $\begin{array}{l}\text { Ultrasonication } \\
\text { time (min) }\end{array}$ & $\begin{array}{l}\text { Reactor } \\
\mathrm{T}\left({ }^{\circ} \mathrm{C}\right)\end{array}$ & Total TG ${ }^{2}$ & FFA & $\mathrm{MeOH}$ & $\mathrm{KOH}$ & TG & $\mathrm{DG}^{3}$ & $\mathrm{MG}^{4}$ & $\mathrm{C}_{19} \mathrm{H}_{34} \mathrm{O}_{2}$ & $\mathrm{C}_{19} \mathrm{H}_{36} \mathrm{O}_{2}$ & $\mathrm{C}_{17} \mathrm{H}_{34} \mathrm{O}_{2}$ & Glycerin & Soap & Water & $\mathrm{MeOH}$ & $\mathrm{KOH}$ \\
\hline 4 & 6 & 40 & 1159.9 & 3.7 & 171.0 & 13.3 & 517.8 & 347.8 & 181.4 & 57.35 & 38.49 & 17.56 & 12.0 & 4.3 & 0.2 & 158.6 & 12.6 \\
\hline 4 & 8 & 40 & 1159.9 & 3.7 & 171.0 & 13.3 & 469.3 & 315.2 & 164.4 & 107.19 & 71.94 & 32.81 & 22.4 & 4.3 & 0.2 & 147.7 & 12.6 \\
\hline 4 & 10 & 40 & 1159.9 & 3.7 & 171.0 & 13.3 & 439.0 & 294.9 & 153.7 & 138.33 & 92.85 & 42.35 & 28.9 & 4.3 & 0.2 & 140.9 & 12.6 \\
\hline 4 & 6 & 50 & 1159.9 & 3.7 & 171.0 & 13.3 & 451.0 & 302.9 & 158.0 & 126.01 & 84.58 & 38.57 & 26.3 & 4.3 & 0.2 & 143.6 & 12.6 \\
\hline 4 & 8 & 50 & 1159.9 & 3.7 & 171.0 & 13.3 & 440.4 & 295.8 & 154.2 & 136.94 & 91.91 & 41.92 & 28.6 & 4.3 & 0.2 & 141.2 & 12.6 \\
\hline 4 & 10 & 50 & 1159.9 & 3.7 & 171.0 & 13.3 & 413.6 & 277.8 & 144.9 & 164.42 & 110.36 & 50.33 & 34.3 & 4.3 & 0.2 & 135.3 & 12.6 \\
\hline 4 & 6 & 60 & 1159.9 & 3.7 & 171.0 & 13.3 & 386.7 & 259.7 & 135.4 & 192.05 & 128.90 & 58.79 & 40.1 & 4.3 & 0.2 & 129.2 & 12.6 \\
\hline 4 & 8 & 60 & 1159.9 & 3.7 & 171.0 & 13.3 & 269.8 & 181.2 & 94.5 & 312.19 & 209.54 & 95.57 & 65.1 & 4.3 & 0.2 & 103.1 & 12.6 \\
\hline 4 & 10 & 60 & 1159.9 & 3.7 & 171.0 & 13.3 & 255.1 & 171.3 & 89.3 & 327.23 & 219.64 & 100.17 & 68.3 & 4.3 & 0.2 & 99.8 & 12.6 \\
\hline 6 & 6 & 40 & 1082.3 & 3.5 & 239.4 & 13.3 & 176.8 & 118.8 & 61.9 & 368.26 & 247.17 & 112.73 & 76.8 & 4.0 & 0.2 & 159.2 & 12.6 \\
\hline 6 & 8 & 40 & 1082.3 & 3.5 & 239.4 & 13.3 & 123.7 & 83.1 & 43.3 & 422.82 & 283.80 & 129.43 & 88.2 & 4.0 & 0.2 & 147.4 & 12.6 \\
\hline 6 & 10 & 40 & 1082.3 & 3.5 & 239.4 & 13.3 & 96.0 & 64.5 & 33.6 & 451.26 & 302.89 & 138.14 & 94.1 & 4.0 & 0.2 & 141.2 & 12.6 \\
\hline 6 & 6 & 50 & 1082.3 & 3.5 & 239.4 & 13.3 & 116.9 & 78.5 & 41.0 & 429.77 & 288.46 & 131.56 & 89.7 & 4.0 & 0.2 & 145.8 & 12.6 \\
\hline 6 & 8 & 50 & 1082.3 & 3.5 & 239.4 & 13.3 & 92.3 & 62.0 & 32.3 & 455.03 & 305.42 & 139.30 & 94.9 & 4.0 & 0.2 & 140.4 & 12.6 \\
\hline 6 & 10 & 50 & 1082.3 & 3.5 & 239.4 & 13.3 & 71.2 & 47.8 & 24.9 & 476.79 & 320.02 & 145.96 & 99.5 & 4.0 & 0.2 & 135.6 & 12.6 \\
\hline 6 & 6 & 60 & 1082.3 & 3.5 & 239.4 & 13.3 & 105.5 & 70.9 & 36.9 & 441.52 & 296.35 & 135.16 & 92.1 & 4.0 & 0.2 & 143.3 & 12.6 \\
\hline 6 & 8 & 60 & 1082.3 & 3.5 & 239.4 & 13.3 & 45.3 & 30.4 & 15.9 & 503.33 & 337.84 & 154.08 & 105.0 & 4.0 & 0.2 & 129.8 & 12.6 \\
\hline 6 & 10 & 60 & 1082.3 & 3.5 & 239.4 & 13.3 & 15.4 & 10.4 & 5.4 & 534.04 & 358.45 & 163.48 & 111.4 & 4.0 & 0.2 & 123.2 & 12.6 \\
\hline 8 & 6 & 40 & 1014.7 & 3.3 & 299.3 & 13.3 & 145.9 & 98.0 & 51.1 & 365.61 & 245.40 & 111.92 & 76.3 & 3.7 & 0.2 & 219.7 & 12.7 \\
\hline 8 & 8 & 40 & 1014.7 & 3.3 & 299.3 & 13.3 & 91.6 & 61.5 & 32.1 & 421.45 & 282.88 & 129.02 & 87.9 & 3.7 & 0.2 & 207.5 & 12.7 \\
\hline 8 & 10 & 40 & 1014.7 & 3.3 & 299.3 & 13.3 & 51.2 & 34.4 & 17.9 & 462.89 & 310.69 & 141.70 & 96.6 & 3.7 & 0.2 & 198.5 & 12.7 \\
\hline 8 & 6 & 50 & 1014.7 & 3.3 & 299.3 & 13.3 & 128.6 & 86.4 & 45.0 & 383.41 & 257.35 & 117.37 & 80.0 & 3.7 & 0.2 & 215.8 & 12.7 \\
\hline 8 & 8 & 50 & 1014.7 & 3.3 & 299.3 & 13.3 & 71.0 & 47.7 & 24.9 & 442.53 & 297.03 & 135.47 & 92.3 & 3.7 & 0.2 & 202.9 & 12.7 \\
\hline 8 & 10 & 50 & 1014.7 & 3.3 & 299.3 & 13.3 & 53.8 & 36.1 & 18.8 & 460.27 & 308.93 & 140.90 & 96.0 & 3.7 & 0.2 & 199.1 & 12.7 \\
\hline 8 & 6 & 60 & 1014.7 & 3.3 & 299.3 & 13.3 & 39.4 & 26.5 & 13.8 & 475.05 & 318.85 & 145.42 & 99.1 & 3.7 & 0.2 & 195.8 & 12.7 \\
\hline 8 & 8 & 60 & 1014.7 & 3.3 & 299.3 & 13.3 & 12.8 & 8.6 & 4.5 & 502.38 & 337.20 & 153.79 & 104.8 & 3.7 & 0.2 & 189.9 & 12.7 \\
\hline 8 & 10 & 60 & 1014.7 & 3.3 & 299.3 & 13.3 & 3.5 & 2.3 & 1.2 & 511.97 & 343.63 & 156.72 & 106.8 & 3.7 & 0.2 & 187.8 & 12.7 \\
\hline
\end{tabular}

and ultrasonication time of $10 \mathrm{~min}$. The conversion efficiency marginally increased to $99.31 \%$ with increasing the alcohol/oil molar ratio to 8:1. It should be quoted that the optimum alcohol/oil molar ratio is profoundly affected by various factors including system configuration, reactor volume, catalyst properties, operating temperature, etc. (Mootabadi et al., 2010).

Increasing the ultrasonication time and liquid media temperature increased the conversion efficiency (Fig. 3). The longer exposure time to ultrasonic irradiations apparently enhanced the emulsification of the immiscible reactants (alcohol-oil phases) due to an increase in the number of cavitation microbubbles formed, leading to the higher yield of fatty acid methyl esters. In addition, increasing the liquid temperature enhanced the reaction rate since reactant molecules could attain a sufficient amount of energy to prevail the energy barrier. Furthermore, increasing the reactor temperature increased the miscibility and solubility of methanol in the WCO, leading to an increase in the kinetic energy of the reactants and their better contact. This could also be attributed to the fact that the diffusion resistance between the different phases of the mixture decreased owing to a drop in viscosity at higher temperatures (Gupta et al., 2015). However, further increase of the liquid media temperature beyond $60{ }^{\circ} \mathrm{C}$ might have negatively impacted the cavitational effects of the ultrasound irradiations, lowering the conversion efficiency unfavorably (Maran and Priya, 2015). In fact, this occurred because of the low boiling temperature of methanol, i.e., $64.7^{\circ} \mathrm{C}$ (Lee et al., 2011). In better words, elevating the liquid media temperature beyond an optimal value could lead to evaporation of a portion of the involved alcohol, decreasing the possibility of successful collision of triglyceride molecules with the alcohol. This could also lead to the supersaturation of cavitational bubbles with methanol vapor, resulting in their implosion with lower intensity (Gupta et al., 2015). Furthermore, increasing the liquid medium temperature could have also reduced the cavitational effect by facilitating the propagation and dissipation of the ultrasound waves (Korkut and Bayramoglu, 2016). These clearly indicate why optimum operational variables should be exclusively applied for different transesterification systems. 

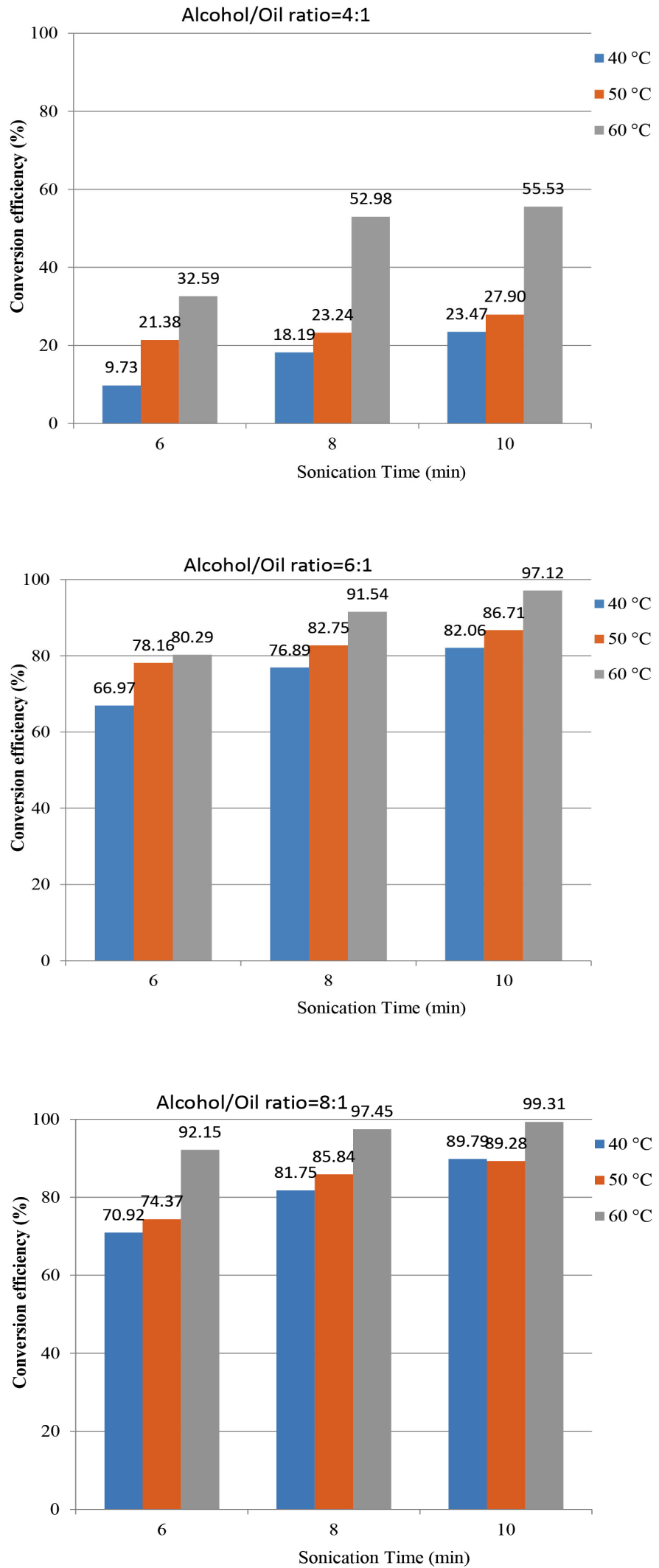

Fig.3. The effects of experimental variables on the conversion efficiency of the WCO to biodiesel.
For better understanding of the effects of various operational conditions on the conversion efficiency of the rector, a linear regression model was developed. First, the experimental variables were normalized between 1 and 2 using the following equation (Eq. 2):

$X^{\prime}=\frac{X-X_{\min }}{X_{a x}-X_{\min }}+1$ 3):

The developed model for the conversion efficiency was as follows (Eq.

$\mathrm{CE}(\%)=-70.37+57.32 \times \mathrm{M}+13.85 \times \mathrm{U}+19.91 \times \mathrm{T}$

where $\mathrm{CE}$ is the conversion efficiency while $\mathrm{M}, \mathrm{U}$, and $\mathrm{T}$ are the normalized alcohol/oil molar ratio, normalized ultrasonication time, and normalized reactor temperature, respectively.

Although the developed model fitted acceptably to the conversion efficiency with a multiple $\mathrm{R}$ value of about 0.90 , advanced modeling systems allowing accurate prediction of this important parameter should be examined in future studies. According to the developed model, the main contributors to the conversion efficiency were (in a descending order of importance): alcohol/oil molar ratio, reactor temperature, and ultrasonication time. However, the interaction of these factors on the conversion efficiency should be scrutinized using advanced statistical tools.

Table 3.

The electrical energy utilized by various components of the reactor at different alcohol/oil molar ratios, ultrasonication times, and reactor temperatures.

\begin{tabular}{|c|c|c|c|c|c|c|}
\hline \multicolumn{3}{|c|}{ Operational conditions } & \multicolumn{4}{|c|}{ Energy consumption $(\mathbf{k J})$} \\
\hline $\begin{array}{l}\text { Alcohol/oil } \\
\text { molar ratio }\end{array}$ & $\begin{array}{l}\text { Sonication } \\
\text { time (min) }\end{array}$ & $\begin{array}{l}\text { Reactor T } \\
\left({ }^{\circ} \mathrm{C}\right)\end{array}$ & Module & Heater & Thermostat & Total \\
\hline $4: 1$ & 6 & 40 & 11.16 & 162.50 & 6.85 & 180.51 \\
\hline $4: 1$ & 8 & 40 & 14.88 & 162.50 & 8.05 & 185.43 \\
\hline $4: 1$ & 10 & 40 & 18.60 & 162.50 & 9.25 & 190.35 \\
\hline $4: 1$ & 6 & 50 & 11.16 & 269.00 & 8.98 & 289.14 \\
\hline $4: 1$ & 8 & 50 & 14.88 & 269.00 & 10.18 & 294.06 \\
\hline $4: 1$ & 10 & 50 & 18.60 & 269.00 & 11.38 & 298.98 \\
\hline $4: 1$ & 6 & 60 & 11.16 & 367.50 & 10.95 & 389.61 \\
\hline $4: 1$ & 8 & 60 & 14.88 & 367.50 & 12.15 & 394.53 \\
\hline $4: 1$ & 10 & 60 & 18.60 & 367.50 & 13.35 & 399.45 \\
\hline $6: 1$ & 6 & 40 & 11.16 & 162.50 & 6.85 & 180.51 \\
\hline $6: 1$ & 8 & 40 & 14.88 & 162.50 & 8.05 & 185.43 \\
\hline $6: 1$ & 10 & 40 & 18.60 & 162.50 & 9.25 & 190.35 \\
\hline $6: 1$ & 6 & 50 & 11.16 & 269.00 & 8.98 & 289.14 \\
\hline $6: 1$ & 8 & 50 & 14.88 & 269.00 & 10.18 & 294.06 \\
\hline $6: 1$ & 10 & 50 & 18.60 & 269.00 & 11.38 & 298.98 \\
\hline $6: 1$ & 6 & 60 & 11.16 & 367.50 & 10.95 & 389.61 \\
\hline $6: 1$ & 8 & 60 & 14.88 & 367.50 & 12.15 & 394.53 \\
\hline $6: 1$ & 10 & 60 & 18.60 & 367.50 & 13.35 & 399.45 \\
\hline $8: 1$ & 6 & 40 & 11.16 & 162.50 & 6.85 & 180.51 \\
\hline $8: 1$ & 8 & 40 & 14.88 & 162.50 & 8.05 & 185.43 \\
\hline $8: 1$ & 10 & 40 & 18.60 & 162.50 & 9.25 & 190.35 \\
\hline $8: 1$ & 6 & 50 & 11.16 & 269.00 & 8.98 & 289.14 \\
\hline $8: 1$ & 8 & 50 & 14.88 & 269.00 & 10.18 & 294.06 \\
\hline $8: 1$ & 10 & 50 & 18.60 & 269.00 & 11.38 & 298.98 \\
\hline $8: 1$ & 6 & 60 & 11.16 & 367.50 & 10.95 & 389.61 \\
\hline $8: 1$ & 8 & 60 & 14.88 & 367.50 & 12.15 & 394.53 \\
\hline $8: 1$ & 10 & 60 & 18.60 & 367.50 & 13.35 & 399.45 \\
\hline
\end{tabular}

Table 3 summarizes the electrical energy utilized by various components of the reactor under different experimental conditions. Figure 4 also manifests the effects of experimental variables on the specific energy consumption during the conversion of WCO to biodiesel using the 

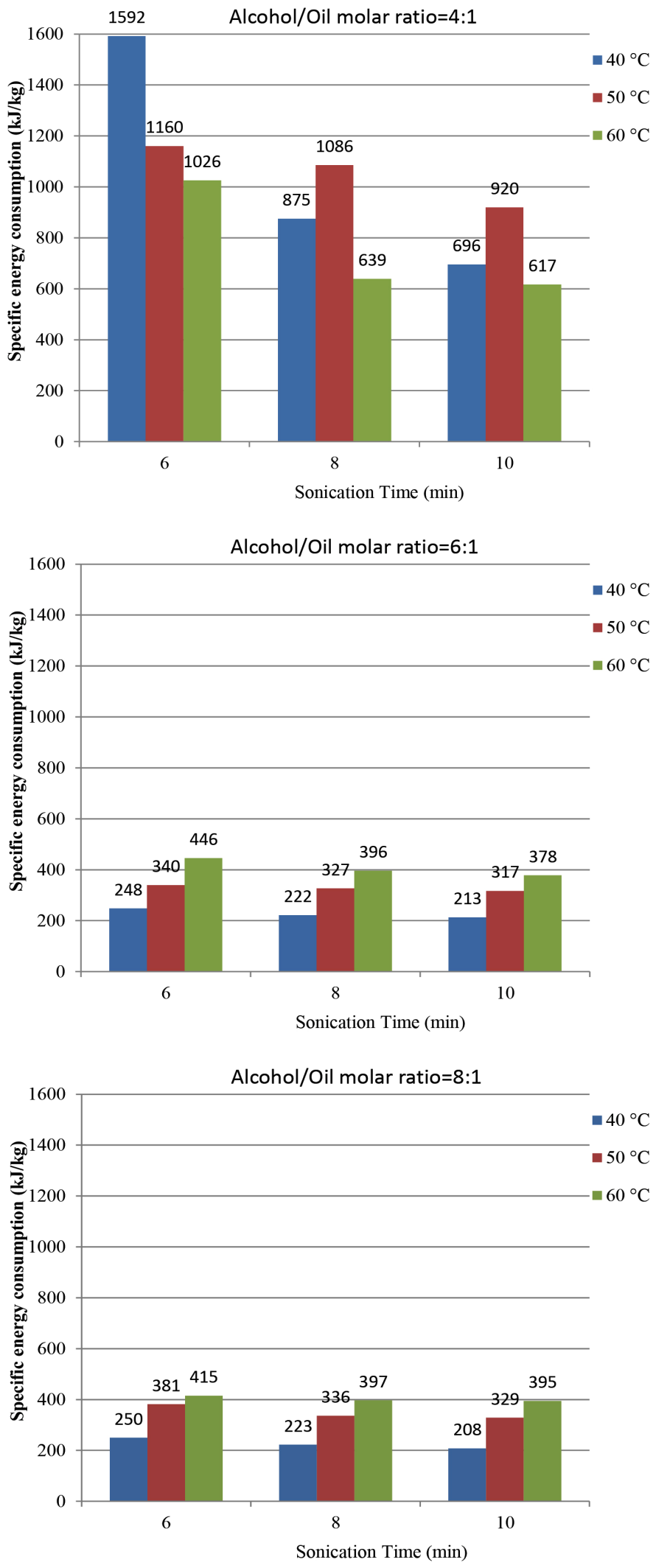

Fig.4. The effects of experimental variables on the specific energy consumption during piezoelectric-based ultrasonic conversion of WCO to biodiesel. piezoelectric-based ultrasonic reactor. The total energy utilized for the transesterification of WCO by the developed piezoelectric-based ultrasonic reactor ranged from a minimum value of $180.51 \mathrm{~kJ}$ to a maximum value of $399.45 \mathrm{~kJ}$. Increasing the ultrasonication time and reactor temperature increased the total energy utilization of the transesterification process. While, the total energy utilized by the reactor was not affected by alcohol/oil molar ratio. The total energy consumption cannot be a perfect metric in order to make a decision on the experimental variables. To address this issue, the specific energy consumption was also defined for decision making on the operational variables of the reactor by considering the total energy utilized and the amount of biodiesel produced during the transesterification process.

The specific energy consumption values varied between $208 \mathrm{~kJ} / \mathrm{kg}$ and $1592 \mathrm{~kJ} / \mathrm{kg}$. In general, the specific energy consumption decreased by increasing the ultrasonication time and alcohol/oil molar ratio, while it was increased by enhancing the reactor temperature. The lowest specific energy consumption $(378 \mathrm{~kJ} / \mathrm{kg}$ ) while meeting the ASTM standard, i.e., $96.5 \%$ conversion efficiency, was found at the reactor temperature of 60 ${ }^{\circ} \mathrm{C}$, ultrasonication time of $10 \mathrm{~min}$, and alcohol/oil molar ratio of $6: 1$. The second lowest specific energy consumption while meeting the ASTM standard was determined at $395 \mathrm{~kJ} / \mathrm{kg}$ for reactor temperature of $60{ }^{\circ} \mathrm{C}$, ultrasonication time of $10 \mathrm{~min}$, and alcohol/oil molar ratio of 8:1. Between these conditions, the first one could be suggested as optimal conditions for biodiesel production from WCO using the developed reactor due to the lower alcohol utilization and the trivial difference in the conversion efficiency.

Nevertheless, it is worth highlighting that comprehensive technoeconomic assessments should still be performed using advanced tools like exergy and its extension as well as life cycle assessment in order to find the most cost-effective and environment-friendly arrangements/conditions of the proposed ultrasonic reactor technology. In fact, the conversion efficiency of ultrasound-assisted reactors being developed for biodiesel production could be optimized by manipulating the operational parameters of the reactor such as alcohol/oil molar ratio, reaction temperature, ultrasonication time, etc. However, it should be emphasized that multi-objective optimization studies using advanced evolutionary- or knowledge-based techniques are required to lower the specific energy consumption and increase the conversion efficiency, simultaneously, while ensuring that the ASTM standards are met for the final fuel as well.

In order to further scrutinize the effect of operational variables on the specific energy consumption (SE) of the WCO transesterification process, a linear mathematical model $(\mathrm{R}=0.77)$ was also developed as follows $(\mathrm{Eq}$. 4):

$\mathrm{SE}(\mathrm{kJ} / \mathrm{kg})=1.75-0.63 \times \mathrm{M}-0.20 \times \mathrm{U}+0.02 \times \mathrm{T}$

Eq. 4

According to the developed model, the order based on which the operational variables impacted the specific energy consumption was: alcohol/oil molar ratio > ultrasonication time > reactor temperature. In fact, both alcohol/oil molar ratio and ultrasonication time decreased the specific energy consumption, while this criterion was negatively affected by reactor temperature.

Taking in consideration the results obtained from the conversion efficiency and specific energy consumption, the optimum conditions for biodiesel production were alcohol/oil molar ratio of $6: 1$, ultrasonication time of $10 \mathrm{~min}$, and reaction temperature of $60{ }^{\circ} \mathrm{C}$, yielding a conversion efficiency of $97.12 \%$. The optimal conditions obtained herein were also compared with those reported in the literature in order to further evaluate the suitability of the developed piezoelectric-based ultrasonic reactor for synthesizing biodiesel (Table 4). Obviously, the low power, high frequency ultrasonic reactor developed in the present study outperformed most of the systems reported in the published literature in terms of processing time, conversion efficiency, and power requirement. It is interesting to note that the optimal alcohol/oil molar ratio found through this study was markedly lower than those previously reported in this domain. This could be ascribed to the intensified reaction resulted from high frequency ultrasonication which in turns lowered the amount of alcohol required to maintain the rate of transesterification process in an acceptable level. 
Table 4.

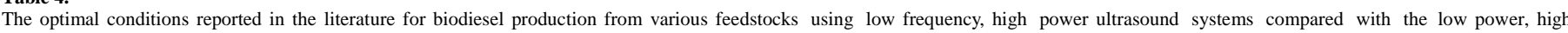
frequency piezoelectric-based ultrasonic system developed herein.

\begin{tabular}{|c|c|c|c|c|}
\hline Feedstock & Catalyst & Optimum reaction condition & Conversion efficiency $(\%)$ & Reference \\
\hline Palm oil & $\mathrm{SrO}$ & $\mathrm{C}=3 \mathrm{wt} \%, \mathrm{M}=15: 1, \mathrm{~T}=65^{\circ} \mathrm{C}, \mathrm{t}=60 \mathrm{~min}, \mathrm{~F}=20 \mathrm{kHz}, \mathrm{P}_{\max }=200 \mathrm{~W}$ & 95.2 & Mootabadi et al. (2010) \\
\hline Palm oil & $\mathrm{BrO}$ and $\mathrm{SrO}$ & $\begin{array}{l}\mathrm{C}=2.8 \mathrm{wt} \%, \mathrm{M}=9: 1, \mathrm{~T}=65^{\circ} \mathrm{C}, \mathrm{t}=50 \mathrm{~min}, \mathrm{~F}=20 \mathrm{kHz}, \mathrm{P}_{\max }=200 \mathrm{~W} \text { with amplitudes } \\
70 \% \text { and } 80 \% \text { for } \mathrm{BaO} \text { and } \mathrm{SrO}\end{array}$ & 95 & Salamatinia et al. (2010) \\
\hline Jatropha oil & $\mathrm{Ca}(\mathrm{OMe})_{2}$ & $\mathrm{C}=5.5 \mathrm{wt} \%, \mathrm{M}=11: 1, \mathrm{~T}=64^{\circ} \mathrm{C}, \mathrm{t}=60 \mathrm{~min}, \mathrm{~F}=35 \mathrm{kHz}, \mathrm{P}=35 \mathrm{~W}$ & 96 & Choudhury et al. (2014) \\
\hline WCO & Calcium diglyceroxide & $\mathrm{C}=1 \mathrm{wt} \%, \mathrm{M}=9: 1, \mathrm{~T}=60^{\circ} \mathrm{C}, \mathrm{t}=30 \mathrm{~min}, \mathrm{~F}=22 \mathrm{kHz}, \mathrm{P}=120$ with $50 \%$ duty cycle & 93.5 & Gupta et al. (2015) \\
\hline Canola oil & Dolomite and $\mathrm{CaO}$ & $\begin{array}{l}\mathrm{C}=5 \mathrm{wt} \%, \mathrm{M}=9: 1, \mathrm{~T}=60^{\circ} \mathrm{C}, \mathrm{t}=90 \mathrm{~min}, \mathrm{~F}=20 \mathrm{kHz}, \mathrm{P}=45 \mathrm{~W} \text { for dolomite } \\
\mathrm{C}=3 \mathrm{wt} \%, \mathrm{M}=9: 1, \mathrm{~T}=60^{\circ} \mathrm{C}, \mathrm{t}=75 \mathrm{~min}, \mathrm{~F}=20 \mathrm{kHz}, \mathrm{P}=45 \mathrm{~W} \text { for } \mathrm{CaO}\end{array}$ & $\begin{array}{l}97.4 \text { for dolomite } \\
95.5 \text { for } \mathrm{CaO}\end{array}$ & $\begin{array}{l}\text { Korkut and Bayramoglu } \\
\text { (2016) }\end{array}$ \\
\hline WCO & Immobilized novozym 435 & $\mathrm{C}=3 \mathrm{w} / \mathrm{v} \%, \mathrm{M}=9: 1, \mathrm{t}=180 \mathrm{~min}, \mathrm{~F}=20 \mathrm{kHz}, \mathrm{P}=80 \mathrm{~W}$ with $60 \%$ duty cycle & 96.1 & Subhedar and Gogate (2016) \\
\hline WCO & $\mathrm{KOH}$ & $\mathrm{C}=1 \mathrm{w} / \mathrm{v} \%, \mathrm{M}=6: 1, \mathrm{t}=10 \mathrm{~min}, \mathrm{~F}=1700 \mathrm{kHz}, \mathrm{P}=31 \mathrm{~W}$ & 97.1 & Present study \\
\hline
\end{tabular}

C: Catalyst, t: reaction time, F: frequency, P: power

Moreover, a quick glance at the published literature revealed that the amount of catalyst used by most research studies was often higher than what applied in the current survey (Table 4). This finding could be attributed to the adequate contact among the reactants owing to the uniform mixing patterns or dispersions resulted from the cavitational events, reducing the quantity of catalyst required to achieve a high conversion efficiency. Therefore, by using the piezoelectric-based ultrasound technology, an excess use of catalyst as well as the consequent down-stream difficulties can be avoided. Overall, the transesterification of WCO under low power, high frequency ultrasonic irradiation could be an efficient, time-saving, and cost-effective method for synthesizing biodiesel. This could be ascribed to the severe turbulence and liquid circulation currents generated owing to the propagation of high frequency ultrasonic waves within liquid medium, intensifying the emulsification process more intensely compared with the low frequency ultrasonic systems.

\section{Conclusions}

This study successfully demonstrated the reliability and productivity of a novel low power, high frequency piezoelectric-based ultrasonic reactor for intensification of the transesterification process. The developed reactor converted over $97 \%$ of the triglycerides to methyl esters at alcohol/oil molar ratio of $6: 1$ and reaction temperature of $60{ }^{\circ} \mathrm{C}$ within 10 min with an specific energy consumption of $378 \mathrm{~kJ} / \mathrm{kg}$. Although the transesterification time was comparatively lower than those of high power, low frequency ultrasound systems reported in the published literatures, the obtained conversion efficiency herein satisfactorily met the ASTM standard. Therefore, the high frequency ultrasound system outperformed those previously reported in terms of conversion efficiency, energy requirement, and processing time. This revealed that the piezoelectric-based ultrasonic reactor could assuredly replace the low frequency ultrasonic horn and bath systems reported in the literature for biodiesel production.

Nevertheless, future studies should scrutinize the cost-effectiveness and eco-friendly features of ultrasound-assisted biodiesel production systems though advanced engineering tools like exergy analysis and life cycle assessment approach. Moreover, future research works should also be directed towards the techno-economic assessment of large-scale industrial biodiesel production plants using the proposed low power, high frequency ultrasound technology.

\section{Acknowledgements}

The author would like to acknowledge the supports provided by SGP/GEF/UNDP (Project No.: IRA/SGP/OP5/Y3/STAR/CC/13/13(189)) and Biofuel Research Team (BRTeam) for constructing the ultrasonic reactor. We would also like to extend our appreciation to University of Tehran and Iranian Biofuel Society (IBS) for supporting this study. The authors are also thankful to Dr. Majid Mohadesi (Kermanshah University of Technology, Iran) and Eng. Ali Dadak for providing the GC internal standard and assisting with the graphical designs, respectively.

\section{References}

[1] Aghbashlo, M., Demirbas, A., 2016. Biodiesel: hopes and dreads Biofuel Res. J. 3(2), 379

[2] Aghbashlo, M., Tabatabaei, M., Mohammadi, P., Pourvosoughi, N. Nikbakht, A.M., Goli, S.A.H., 2015. Improving exergetic anc sustainability parameters of a DI diesel engine using polymer waste dissolved in biodiesel as a novel diesel additive. Energy Convers. Manage. 105, 328-337.

[3] Choudhury, H.A., Goswami, P.P., Malani, R.S., Moholkar, V.S., 2014. Ultrasonic biodiesel synthesis from crude Jatropha curcas oi with heterogeneous base catalyst: mechanistic insight and statistical optimization. Ultrason. Sonochem. 21(3), 1050-1064.

[4] Collins, K., 2008. The role of biofuels and other factors in increasing farm and food prices-a review of recent developments with a focus on feed grain markets and market prospects. Supporting material for a review conducted by Kraft Foods Global, Inc.

[5] Deshmane, V.G., Gogate, P.R., Pandit, A.B., 2008. Ultrasoundassisted synthesis of biodiesel from palm fatty acid distillate. Ind Eng. Chem. Res. 48(17), 7923-7927

[6] Gupta, A.R., Yadav, S.V., Rathod, V.K., 2015. Enhancement in biodiesel production using waste cooking oil and calcium diglyceroxide as a heterogeneous catalyst in presence of ultrasound. Fuel. 158, 800-806.

[7] Korkut, I., Bayramoglu, M., 2016. Ultrasound assisted biodiese production in presence of dolomite catalyst. Fuel. 180, 624-629.

[8] Lee, S.B., Lee, J.D., Hong, I.K., 2011. Ultrasonic energy effect on vegetable oil based biodiesel synthetic process. J. Ind. Eng. Chem. 17(1), 138-143.

[9] Maddikeri, G.L., Pandit, A.B., Gogate, P.R., 2013. Ultrasounc assisted interesterification of waste cooking oil and methyl acetate for biodiesel and triacetin production. Fuel Process. Technol. 116, 241-249.

[10] Maran, J.P., Priya, B., 2015. Comparison of response surface methodology and artificial neural network approach towards efficient ultrasound-assisted biodiesel production from muskmelon oil. Ultrason. Sonochem. 23, 192-200.

[11] Michelin, S., Penha, F.M., Sychoski, M.M., Scherer, R.P., Treichel, H., Valério, A., Di Luccio, M., de Oliveira, D. Oliveira, J.V., 2015 
Kinetics of ultrasound-assisted enzymatic biodiesel production from Macauba coconut oil. Renew. Energy. 76, 388-393.

[12] Mitchell, D., 2008. A note on rising food prices. world bank policy research working paper series. Washington DC: the World Bank. Development Prospects Group.

[13] Mootabadi, H., Salamatinia, B., Bhatia, S., Abdullah, A.Z., 2010. Ultrasonic-assisted biodiesel production process from palm oil using alkaline earth metal oxides as the heterogeneous catalysts. Fuel. 89(8), $1818-1825$

[14] Ramachandran, K., Suganya, T., Gandhi, N.N., Renganathan, S., 2013. Recent developments for biodiesel production by ultrasonic assist transesterification using different heterogeneous catalyst: a review. Renew. Sust. Energy Rev. 22, 410-418.

[15] Salamatinia, B., Abdullah, A.Z., Bhatia, S., 2012. Quality evaluation of biodiesel produced through ultrasound-assisted heterogeneous catalytic system. Fuel Process. Technol. 97, 1-8.
[16] Santos, F.F., Malveira, J.Q., Cruz, M.G., Fernandes, F.A., 2010 Production of biodiesel by ultrasound assisted esterification of Oreochromis niloticus oil. Fuel. 89(2), 275-279.

[17] Subhedar, P.B., Gogate, P.R., 2016. Ultrasound assisted intensification of biodiesel production using enzymatic interesterification. Ultrason. Sonochem. 29, 67-75.

[18] Tiwari, A.K., Kumar, A., Raheman, H., 2007. Biodiesel production from jatropha oil (Jatropha curcas) with high free fatty acids: an optimized process. Biomass Bioenergy. 31(8), 569-575.

[19] Wang, Y., Ou, S., Liu, P., Xue, F., Tang, S., 2006. Comparison of two different processes to synthesize biodiesel by waste cooking oil. J. Mol. Catal. A: Chem. 252(1-2), 107-112.

[20] Yin, X., Ma, H., You, Q., Wang, Z., Chang, J., 2012. Comparison of four different enhancing methods for preparing biodiesel through transesterification of sunflower oil. Appl. Energ. 91(1), 320-325. 